\title{
Evaluation of Ultrasound Therapeutic Effect on Patients with Carpal Tunnel Syndrome Attending in a Tertiary Care Hospital of Bangladesh
}

\author{
Siddique $\mathrm{N}^{\mathrm{a}}$, Mishu FA ${ }^{\mathrm{b}}$, Rahman $\mathrm{S}^{\mathrm{c}}$, Zaman $\mathrm{AKA}^{\mathrm{d}}$
}

\begin{abstract}
Background: Carpal tunnel syndrome is a common condition in medical practice. Ultrasound therapy is a common non-surgical treatment of carpal tunnel syndrome including other modalities like the use of antiinflammatory agents and exercise. This study was designed to evaluate the effect of ultrasound therapy for the relief of symptoms of patients with carpal tunnel syndrome.

Methods: This was a randomized controlled trial. This study as conducted in Department of Physical Medicine and Rehabilitation of Bangabandhu Sheikh Mujib Medical University, Dhakaduring the period from March 2014 to August 2014 to evaluate the effect of ultrasound therapy on patients of carpal tunnel syndrome. Total 110 subjects were participated in this study and they were selected randomly. The patients were divided in two groups by lottery. For group A patients treatment schedule (Ultrasound therapy + Exercise + Wrist splint + NSAIDs) and group B (Exercise+ Wrist splint + NSAIDs) were applied for a period of 6 weeks. Group A were compared to group B byVisual Analog Scale after 3weeks and 6weeks of treatment. Statistical analysis of the finding was done with the help of statistical package for social science version (SPSS) 19. The student t test used to analyze the level of significance, $p<0.05$.

Results: This study showed mean visual analogue scale (VAS) at pretreatment (W0) in group-A was $6.42 \pm 1.23$ and in group- $B$ was $6.17 \pm 0.74$. Group- $A$ was $1.82 \pm 0.43$ and in group- $B$ was $3.1 \pm 0.23$ in their follow up after 3 weeks (W 3). Mean Visual Analogue scale in groupA-was 1.71( \pm 0.52$)$ and in group- $B$ was 2.52( \pm 0.49$)$ at 2 nd follow up (W 6) after 6 weeks. So these result reveled that group-A is significantly better than group-B.

Conclusion: This study revealed that continuous mode of US therapy with exercise, wrist splint, NSAIDs have better outcome in case of Carpal tunnel syndrome patients.
\end{abstract}

Key Word: Carpal tunnel syndrome, visual analogue scale.

(BIRDEM Med J 2019; 9(1):70-73)

\section{Author Information}

a. Dr. Nadia Siddiquee, Senior Medical Officer, Department of Physical Medicine, Bangladesh Institute of Research\& Rehabilitation In Diabetes, Endocrine \& Metabolic Disorders (BIRDEM) Dhaka, Bangladesh.

b. Dr. Farzana Akonjee Mishu, Assistant Professor, Department of Physiology and Molecular Biology, Bangladesh Institute of Research\& Rehabilitation In Diabetes, Endocrine \& Metabolic Disorders (BIRDEM) Dhaka, Bangladesh.

c. Prof. Sohely Rahman, Department of Physical Medicine. Dhaka Medical College.

d. Dr. Abul Khan Ahmed Zaman, Assistant Professor, Department of Physical Medicine, Bangladesh Institute of Research\& Rehabilitation In Diabetes, Endocrine \& Metabolic Disorders (BIRDEM) Dhaka, Bangladesh.

Address of correspondence: Dr. Nadia Siddiquee, Senior Medical Officer, Department of Physical Medicine, Bangladesh Institute of Research\& Rehabilitation In Diabetes, Endocrine \& Metabolic Disorders (BIRDEM) Dhaka, E-mail: nadia.birdem@gmail.com

Received: October 8, 2018

Accepted: October 31, 2018

\section{Introduction}

Carpal tunnel syndrome (CTS) is a condition where one of two main nerves in the wrist is compressed, which can lead to pain in the hand, wrist and sometimes forearm and numbness and tingling in the thumb, index or other fingers. In advanced cases some of the muscles of the hand can become weak. ${ }^{1}$ The carpal tunnel is an anatomic passageway bounded dorsally and laterally by the hemicircular carpal bones and on the palmer surface by the transverse carpal ligament. CTS is due to compression of the median nerve as it passes from the forearm to the palm, beneath the transverse carpal ligament. ${ }^{2} \mathrm{CTS}$ is the most common peripheral entrapment neuropathy with prevalence rates $21.5 \%$ (overall), 32.5\% (technicians) and 12\% (attainders). The rate increases with increasing age and years of 
employment and it affects women more than men.The prevalence of CTS was found to be $13.1 \%$ among computer professionals. ${ }^{3}$ Following treatment approaches commonly used in CTS have remained essentially the same for years: (1) immobilization of the hand by splinting in the neutral position; (2) injection of steroids just proximal to and into the carpal tunnel; and (3) decompression of the median nerve by release of the transverse carpal ligament. Other conservative treatments include adjusting the work environment, nonsteroidal anti-inflammatory drugs (NSAIDs), therapeutic ultrasound, manipulation, nerve and tendon glides, serial night splinting, stretching and strengthening exercise of affected hand. ${ }^{2}$ Ultrasound is the most widely used treatment modality in physical medicine in management of CTS. There are satisfactory short to medium term effects due to ultrasound treatment in patients with mild to moderate CTS. ${ }^{4}$ Ultrasound is a physical therapy agent commonly used to increase temperature in deep tissue. The biologic effects observed when mammalian tissues are exposed to ultrasound include changes in blood flow rates, tissue metabolism, nerve function, the extensibility of connective tissue and the permeability of biologic membranes. ${ }^{5}$ The effects of ultrasound on nervous tissue are follows: it selectively heats peripheral nerves, may alter or block impulse conduction and may increase membrane permeability and tissue metabolism. The thermal effect of ultrasound may cause pain relief. ${ }^{4,6,7}$ Ultrasound at therapeutic intensities ranging from 0.1 to $2.5 \mathrm{w} / \mathrm{cm}^{2}$ (continuous) is used for its effects on soft tissue healing. ${ }^{8,9}$

CTSisone of the common problems encountered in industrialized populations. The risk of disability is so great that it is not only a costly burden to society but also loss of productivity. Among the treatment option in CTS ultrasound therapy is safe, simple and cheaper. The effect of ultrasound therapy in case of carpal tunnel syndrome has not been evaluated in Bangladeshi population. So, this systemic study evaluatedthe effect of ultrasound therapy for the CTS for relieving symptoms. The result may have implications for selecting appropriate treatment modalities and management plan for patients suffering from complications of carpal tunnel syndrome in Bangladesh.

\section{Methods}

This randomized controlled trial was carried out from March 2014 to August 2014 in the department of
Physical Medicine and Rehabilitation of Bangabandhu Sheikh Mujib Medical University, Dhaka. Total 110 present subjects were selected immediately after the examination; the patients were randomized by drawing lottery from outdoor referral patient irrespective of sexes in between 20 to 60 years of age and $\mathrm{BMI}<25 \mathrm{~kg} / \mathrm{m}^{2}$ having CTS. Study subjects who fulfilled these following criteria were selected for this study i)Pain at palmer aspect of wrist more than 3 months, Tingling and numbness of lateral $3 \frac{1}{2}$ fingers Clinically and electro physiologically diagnosed as a case of carpal tunnel syndrome .In this study, all participants were divided into 2 groups- - group $\mathrm{A}(\mathrm{n}=55)$ and group $\mathrm{B}(\mathrm{n}=$ 55). Group A participants were treated with Ultrasound therapy + Exercise + Wrist splint + NSAIDs and group B participants were treated with Exercise + Wrist splint + NSAIDs. All medication was checked strictly and intervention was done aseptically. Date were collected by using a structured questionnaire. The participants were assessed at pretreatment, at 1 st follow up after 3 weeks and 2nd follow up after 6 weeks. They are assessed by using Visual Analog Scale (VAS),

VAS is a measurement instrument for subjective characteristics or attitudes that cannot be directly measured. Operationally a VAS is usually a horizontal line, $100 \mathrm{~mm}$ in length, which is scored from 0 to 10 . In VAS patient, he/she describes the visual impression of his/her pain, Zero means no pain at all and 10 means extreme pain as it is not tolerable by the patient. On the other hand 5 mean medium pain and can be tolerated by the patient. Thus they point out the actual point of pain in the scale and it was documented in the data sheet.

This study protocol was approved by two institutional review committee, of Bangabandhu Shekh Mujib Medical University and College of Physicians and surgeons Bangladesh. Data were analyzed by SPSS 19.0 version The results were analyzed statistically and values were expressed as mean $\pm \mathrm{SD}$. The level of significance was determined by employing Student's unpaired $t$ test. Only when the $p$ value was less than 0.05 ; the difference between two groups were considered as statistically significant.

\section{Results}

In this study 49 patients were male and 61 patients were female. After clinical examination study subjects in group-A $20.0 \%$ were localized pain \& $80.0 \%$ were 
radiating pain present. In group-B 31.0\% were localized pain \& $69 \%$ were radiating pain present.

This study showed mean visual analogue scale (VAS) at pretreatment (W0) in group-A was $6.42 \pm 1.23$ and in group-B was $6.17 \pm 0.74 p$ value was $(p>0.05)$ that was not statistically significant. Mean Visual Analogue scales (VAS) in group-A 1st follow up after 3 weeks (W 3) was $1.82 \pm 0.43$ and in group-B was $3.1 \pm 0.23$. p value was $<0.05$ that was statistically significant. Mean Visual Analogue scale (VAS) in group-A 2nd follow up (W 6) after 6 weeks was $1.71( \pm 0.52)$ and in group-B was $2.52( \pm 0.49)$. $p$ value was $(p<0.05)$ that was statistically significant. That means group-A is significantly better than group-B in first follow up and 2nd follow up.

In this study visual analogue scale (VAS) was not statistically significant $(\mathrm{p}>0.05)$ at pretreatment (W0) when compared between group-A and group-B .But after 3 weeks during 1st follow up (W3) and after 6 weeks in $2^{\text {nd }}$ follow up (W6) when visual analogue scale was compared between these two group then $p$ value was $(p<0.001)$ highly significant. That means group-A is significantly better than group-B in first follow up and 2nd follow up.

Table I Age group distribution of the study population $(\mathrm{N}=110)$

\begin{tabular}{lccc}
\hline Age in years & \multicolumn{2}{c}{ Study group } & Total \\
& Group -A (n \%) & Group-B (n \%) & \\
\hline 20-30 years & $06(10.9)$ & $05(9.1)$ & 11 \\
31-40 years & $20(36.4)$ & $10(18.2)$ & 30 \\
41-50 years & $27(49.1)$ & $32(58.2)$ & 59 \\
51-60 years & $02(3.6)$ & $08(14.5)$ & 10 \\
\hline Total & $55(100)$ & $55(100)$ & 110 \\
Mean SD & $49.87( \pm 6.4)$ & $51.72( \pm 6.3)$ & \\
\hline
\end{tabular}

Table 1shows age distribution of the study subjects

Table II Sex distribution of the study population

\begin{tabular}{lccc}
\hline Sex & \multicolumn{2}{c}{ Study group } & Total \\
& Group -A (n \%) & Group-B (n \%) & \\
\hline Male & $25(45.5)$ & $24(43.6)$ & 49 \\
Female & $30(54.5)$ & $31(56.4)$ & 61 \\
\hline
\end{tabular}

Table IIshows sex distribution of the study subjects
Table III Site of Pain

\begin{tabular}{lccc}
\hline Site of Pain & \multicolumn{2}{c}{ Study group } & Total \\
& Group-A (n\%) & Group-B (n\%) & \\
\hline Localized & $11(20)$ & $17(31)$ & 28 \\
Radiating & $44(80)$ & $38(69)$ & 82 \\
\hline Total & $55(100)$ & $55(100)$ & 110 \\
\hline
\end{tabular}

Table IV Mean Visual Analogue scale (VAS) at Pretreatment and after 3 wks and 6 wks follow up $(n=110)$

\begin{tabular}{|c|c|c|c|c|c|}
\hline \multirow{3}{*}{$\begin{array}{l}\text { Visual Analogue } \\
\text { scale (VAS) }\end{array}$} & \multicolumn{5}{|c|}{ Study group } \\
\hline & \multirow{2}{*}{$\begin{array}{l}\text { Group A } \\
\text { Mean } \\
( \pm \text { SD }) \\
\end{array}$} & \multirow{2}{*}{$\begin{array}{l}\text { Group B } \\
\text { Mean } \\
( \pm \mathrm{SD})\end{array}$} & \multicolumn{2}{|c|}{$95 \% \mathrm{CI}$} & \multirow{2}{*}{$\begin{array}{c}\mathrm{P} \\
\text { value }\end{array}$} \\
\hline & & & Lower & Upper & \\
\hline Pretreatment & 6.42 & 6.17 & -0.21 & 0.81 & 0.25 \\
\hline (WO) & $( \pm 1.23)$ & $( \pm 0.74)$ & & & \\
\hline At 1st follow up & 1.82 & 3.1 & -1.34 & -1.05 & $<0.00$ \\
\hline (W3) & $( \pm 0.43)$ & $( \pm 0.23)$ & & & \\
\hline At $2^{\text {nd }}$ follow up & 1.71 & 2.52 & -1.05 & -0.54 & $<0.00$ \\
\hline (W6) & $( \pm 0.52)$ & $( \pm 0.49)$ & & & \\
\hline
\end{tabular}

\section{Discussion}

In this study, US therapy + Exercise +Wrist splint + NSAIDs tends to be more effective than Exercise+ Wrist splint+ NSAIDs in treating CTS patients. Patients who underwent US therapy and a wrist splint not only experienced improvements in their functional status scores compared to those receiving NSAIDs and a wrist splintbut also showed statistically significant improvements in their symptom severity scores and palmer pinch power.Different modes, frequencies and intensities have been used in US therapy for CTS patients. ${ }^{5,10,11,12,13}$ Generally, in US therapy, continuous mode is chosen when the thermal effect is desired, while pulsed mode is applied when the nonthermal effect is preferred. ${ }^{14}$ Although a study reveals symptom improvements after continuous mode US therapy in CTS patients ${ }^{15}$, another study reports prolong distal motor latency and a decrease in motor nerve conduction velocity after treatment with continuous mode US therapy. ${ }^{5}$ These findings implied that though continuous mode US therapy was able to improve the symptoms in CTS patients, selective heating of the median nerve might lead to temporal conduction block. ${ }^{5}$ On the contrary, pulsed mode US therapy effectively enhanced 
peripheral nerve regeneration in an animal study, possibly through the mechanisms of local blood vessel dilatation, nerve sprouting stimulation, Schwann cell activation and chemotactic stimulator release. This study utilized pulsed mode US therapy on CTS patients and observed improvements in subjective symptoms and palmer pinch power, similar to previous studies. ${ }^{12,16}$

The findings of the present study confirm that ultrasound treatment is more effective treatment in patients with carpal tunnel syndrome. They have claimed that these physical agents may facilitate the recovery from carpal tunnel syndrome. ${ }^{17,18}$ The rate of improvement from ultrasound treatment was similar to that reported in other studies such as Chang et al., (2014), Vieraet al.,(2001) .Piazzini et al.,(2007). ${ }^{17,18,19}$ Although there are some contradictory results from other study done by Oztas (1998).Several clinical trials have revealed US therapy has a positive effect on patients with CTS ${ }^{4,15}$ But in the study of Dincer et al., (2009) showed that the combinations of US or LLL Low-level laser therapies with splinting were more effective than splinting alone in treating CTS. However, LLL therapy plus splinting was more advantageous than US therapy plus splinting, especially for the outcomes of lessening of symptom severity, pain alleviation, and increased patientsatisfaction. ${ }^{15}$ However, Cochrane's 2013 review concluded that there is still insufficient evidence to support that US therapy is more effective than placebo or other nonsurgical interventions for CTS.$^{1}$

\section{Conclusion}

To improve the functional status of CTS patients, a combination of Ultrasound therapy+ Exercise + Wrist splint + NSAIDs may be more effective than a combination of Exercise+ Wrist splint + NSAIDs. Since this was an trial, further confirmatory testing is suggested to justify the efficacy of these two treatments.

Conflict of interest: Nothing to declare.

\section{References}

1. Page MJ, O'Connor D, Pitt V, Massy-Westropp N. Therapeutic ultrasound for carpal tunnel syndrome (Review). The Cochrane Library2012(1):2-5

2. .Wilson JK, Sevier TL. A review of treatment for carpal tunnelsyndrome. DisabilRehabil2003; 25: 113-19.

3. Kamaraddi SV, Latti R, Kodliwadmath M, Gowdar S. Determination of the prevalence of carpal tunnel syndrome in the laboratory workers of Jwaharlal Nehru medical college, Belgaum-A cross-sectional study. Asian J ExpBiolSci2010; 1:740-46.

4. Ebenchler GR, Rech K, Halim A, Wiesinger GE, Uhl F, Fialka V. Ultrasound treatment for treating the carpal tunnel syndrome: randomized "sham" controll trial.BMJ1998; 316:731-35.

5. Oztas O, Turan B, Bora I, Karakaya MK. Ultrasound therapy effect in carpal tunnel syndrome. Arch Phys Med Rehabil 1998;79:1540-44.

6. Hong DZ, Liu HH, Yu J. Ultrasound thermotherapy effect on sensory nerve conduction. Arch Phys Med Rehabil 1988; 69:410-14.

7. Madsen PW, Gersten JW. Effect of ultrasound on conduction velocity of peripheral nerves.Arch Phys Med Rehabil 1960; 42: 645-49.

8. Michlovitz SL, Nolan TP. Modalities for Therapeutic Intervention. $4^{\text {th }}$ ed. Philadelphia, PA:F.A. Davis Company, 2005.

9. Sparrow KJ. Therapeutic Ultrasound. $4^{\text {th }}$ ed. Philadelphia, PA: F.A. Davis Company,2005

10. Gerritsen AAM, de Krom MCTFM, Struijs MA, Scholten RJPM, de Vet HCW, Bouter LM. Conservative treatment options for carpal tunnel syndrome: a systematic review of randomised controlled trials. J Neurol 2002; 249: 272-80.

11. Pinar L, Enhos A, Ada S, Gungor N. Can we use nerve gliding exercises in women with carpal tunnel syndrome? AdvTher 2005; 22: 467-75.

12. Bakhtiary AH, Rashidy-Pour A. Ultrasound and laser therapy in the treatment of carpal tunnel syndrome. Aust J Physiother 2004,50:147-51.

13. Horng YS, Hsieh SF, Tu YK, Lin MC, Horng YS, Wang JD. The comparative effectiveness of tendon and nerve gliding exercises in patients with carpal tunnel syndrome: a randomized trial. Am J Phys Med Rehabil 2011; 90: 435-42.

14. Hacobs MA, Austin NM. Principle and process: Splinting the hand and upper extremity. $1^{\text {st }}$ ed.Lipincott Williams and Wilkins Ltd.2002;280-81.

15 Dincer U, CakarE, Kiralp MZ, Kilac H, Dursun H. The effectiveness of conservative treatments of carpal tunnel syndrome: splinting, ultrasound, and low-level laser therapies. Photomed Laser Surg 2009, 27: 119-25.

16. Levine DW, Simmons BP, Koris MJ,Daltroy LH, Hohl GG, Fossel AH et al. A self - Administered questionnaire for the assessment of severity of symptoms and functional status in carpal tunnel syndrome.J Bone and Joint Surgery 1993; 75: 1585-92.

17. Chang Y, Hsieh S, Horng Y, Chen H, Lee K, HorngY. Comparative effectiveness of ultrasound and paraffin therapy in patients with carpal tunnel syndrome: a randomized trial BMC Musculoskeletal Disord 2014;15:2-7.

18. Viera Aleman C, Puron E, Hamilton ML, Santos Anzorandia C, Navarro A, Pineda Ortiz I. Evaluation of motor and sensory neuroconduction of the median nerve in patients with carpal tunnel syndrome treated with non-coherent light emitted by gallium arsenic diodes. Revue Neurologique2001; 32: 717-20.

19. Piazzini DB, Aprile I, Ferrara PE, Bertolini C, Tonali P, Maggi L et al. A systematic review of conservative treatment of carpal tunnel syndrome. ClinRehabil 2007; 21: 299-314.

20. Dyson M. Mechanism involved in therapeutic ultrasound. Physiotherapy 1987; 73: 116-20.

21. Piravej K. Effect of ultrasound thermotherapy in mild to moderate carpal tunnel syndrome. J Med Assoc Thai 2004; 87 (Suppl 2): 100-106. 